\author{
Military Technical College \\ Kobry El-Kobbah \\ Cairo, Egypt
}

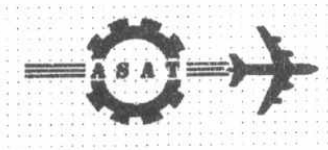

$10^{\text {th }}$ International Conference

On Aerospace Sciences\&

Aviation Technology

\title{
AN INVESTIGATION OF NORMAL PERFORATION OF A SMALL CALIBER PROJECTILE INTO METAL/COMPOSITE LIGHTWEIGHT TARGETS
}

\author{
BY
}

\author{
A. M. Riad", A. I. Fayed" and S. A. Salah"
}

\begin{abstract}
In this paper, an experimental program has been conducted to study the normal perforation of a small caliber projectile into metal/composite targets. This program is concerned with the determination of ballistic resistance for a set of targets, consisting of kevlar/epoxy composite with different thicknesses faced by $1.6 \mathrm{~mm}$-thick duralumin plates. The used textiles (kevlarwith different thicknesses for manucturing the composites have a new weave shape (3D weave ${ }^{T M}$ ), which permits the epoxy resin to diffuse through it. In addition, tensile tests of manufactured composite specimens are performed to determine their mechanical properties.
\end{abstract}

An analytical model has been presented to describe the penetration process of metal/composite lightweight targets and to evaluate their ballistic resistance against small caliber projectiles. The present model consists of two parts; the first is based on energy balance principle for modeling the projectile penetration into a thin metallic plate failed by petalling [1], whereas the second uses the circumferential strain as a failure criterion for modeling the projectile penetration into a composite target [2]. The main equations representing analytical model are presented. These equations are arranged and compiled into a computer program. The input data to run the program are easily determined.

Representative samples of the obtained results are presented with relevant analyses and discussions. The ballistic measurements of the experimental program are compared with the model predictions; good agreement is generally obtained. In addition, new target configurations are constructed and tested; these targets have the capability for defeating the projectile with the highest impact velocity used.

KEY WORDS: Composite mechanics, body armors, impact dynamics, penetration mechanics, and lightweight targets. 


\section{INTRODUCTION}

Nowadays, fiber reinforced composites have been used as armor materials due to their lightweight, good energy absorption and high specific strength. These composites are applied to the structure of modern armor fighting vehicles and body armors. The data of fabric composite materials used in body armors are determined from their direct impact by small caliber projectiles. In the field of ballistic impact, both para-aramides and polyethylene's acquire advanced position among the other metallic and non-metallic lightweight material systems [3].

Various analytical models were developed to describe the projectile penetration through thin metallic, textile composite and metal/composite targets, respectively. These models were essentially concerned with the description of projectile penetration through a specific target and with the determination of its velocity after terminating the penetration process. Paul and Zaid [4] used the momentum balance principle for modeling the penetration of a thin metallic plate by high-speed projectiles. They derived equations representing the magnitude and direction of forces, velocity...etc. as functions of penetration distance for conical projectiles under normal impact. They also extended their work for truncated conical and ogival projectiles [5]. Comparison between their predictions and experimental measurements was found satisfactory.

Landkof and Goldsmith [1] developed an analytical model based on energy balance principle for describing the projectile penetration into a thin metallic plate failed by petalling. In their model, a rigid cylindrical projectile with a conical nose shape was assumed to impact the thin plate at subordnance and ordnance velocities, respectively. Their model was capable of predicting the values of different energy forms absorbed by a thin metallic plate during its perforation. Good correlation was found between their model predictions for projectile residual velocities and the corresponding experimental measurements. They also improved their model predictions by considering the energy dissipated in plate dishing

Vinson and Zukas [6] developed a model determining the actual response of textile fabric panels subjected to ballistic impact by a dense projectile. They formulated stepwise procedures for calculating strains, projectile position, forces and decelerations as functions of penetration time. Their analytical results were in good agreement with experimental data due to the impact of a $5.6 \mathrm{~mm}$ projectile into 1 and 12 plies of nylon and 24 plies of Kevlar-29 textile, respectively. Taylor and Vinson [2] extended the model of Ref. [6] by determining the material properties of a target and the geometry of a deflected cone at each time step, allowing a complete description of the impact event. They also performed ballistic tests by impacting 5.6 and $9 \mathrm{~mm}$ bullets against single and multi-layered Kevlar-29 fabrics, respectively, to assess their model predictions.

Zhu et al. [7] developed an analytical model describing the normal impact and perforation of conical- tipped hard steel cylinder into laminated Kevlar-29-polyster targets. They modeled the dissipative mechanisms including indentation of striker tip, bulging at the surface, fiber failure, delamination and friction using simplified assumptions. They divided the impact event into three consecutive phases; these were indentation, perforation and exit phases. They also performed an experimental program in which they measured the ballistic limits and projectile velocity after perforating the tested laminated. Good agreement was obtained between their model predictions and experimental measurements.

Cunniff [8] developed a parametric model to predict the performance of body armor systems due to their impact by a chunky steel projectile of arbitrary rnass, shape, impact velocity and obliquity. The model, which based on six-dimensional non-linear regression analysis of extensive data for Kevlar-29, was capable of predicting the performance of body armor systems with defined areal densities. The model divided the energy absorbed by the body armor systems into strain and kinetic; the predominated mechanism of energy absorption was through kinetic 
energy transfer. Cunniff also presented his model as a tool for designing, optimization, and evaluating the performance of body armor systems.

Slepyan and Stepanenko [9] presented analytical and numerical models describing the penetration of a metal/fabric target by small caliber projectiles. Comparing the one-dimensional and spatial axisymmetric models for non-linear dynamics of a ply was conducted and their capabilities for using them were discussed. They used a code of a spatial axisymmetric model for composite armor as a tool for simulating the penetration process in actual metal/fabric armors. They obtained the parameters associated with the projectile after perforating the front metallic plate based on experimental data and energy considerations. Comparison of predicted results of their models with the data for actual steel/kevlar armors proved the capabilities of these models to be used as design toois.

In the following, an experimental program has been conducted to manufacture and characterize different thicknesses of kevlar/epoxy composite, to construct duralumin/composite targets with different total thickness and to test these constructed targets by impacting them using small caliber projectiles. An analytical model describing the penetration of a metal/composite target by a small caliber projectile is also presented. This model consists of two parts; the first is based on energy balance principle for modeling the projectile penetration into a thin metallic plate failed by petalling [1], whereas the second uses the circumferential strain as a failure criterion for modeling the projectile penetration into a composite target [2]. Main assumptions are introduced and main equations representing the analytical model are presented. Representative samples of experimental results and corresponding model predictions are presented with relevant analyses and discussions.

\section{EXPRIMENTAL WORK}

An experimental program has been conducted to study the normal perforation of a small caliber projectile into metal/composite targets. The experimental facilities of the shooting range, Chair of Weapons and Ammunition, M.T.C, were used to investigate the ballistic resistance for a set of metal/composite targets against their penetration by small caliber projectiles. In general, the scheme of the experimental work includes the following activities: (a) fabric material choice and composite preparation, (b) characterization of a prepared composite, (c) ballistic tests and measurements, and (d) post-firing examinations.

Fabric Material Choice and Composite Preparation

3D weave $^{T M}$ fabric (kevlar-129) was selected. The reasons of this selection are: (i) the fabric has low density and high uni-axial tensile strength, and (ii) the construction of fabric enables spacing among its yarns, which permits the epoxy spreading easily in-between. Table 1 lists the data of epoxy used to manufacture a composite from the selected fabric.

The main properties of kevlar-129 fabric are listed in Table 2 [7]. The hand lay-up contact molding method was selected for manufacturing the composite (kevlar/epoxy) because: (i) it required minimum equipment, (ii) it could be used for small and large dimensions, and (iii) it produced smooth surfaces. The manufacturing process of such a composite was done using the facilities of Metallurgy Dept., M.T.C., and the technological procedures were listed in Ref. [10]. Table 3 lists the main characteristics of the manufactured kevlar/epoxy composite with different thicknesses.

\section{Characterization of a Prepared Composite}

Characterization of the manufactured composite was only concerned with the determination of its mechanical properties. Tensile tests were performed to determine the stress-strain behavior 
of the manufactured composite. Standard tensile test specimens were prepared from kevlar/epoxy composite with thicknesses of 1,3 , and $6 \mathrm{~mm}$, respectively. Three tensile test specimens were prepared for each composite thickness.

A tensile test program was carried out on the tensile testing machine, Model MTS- 810 with capacity of $100 \mathrm{kN}$, at loading rate of $50 \mathrm{~N} / \mathrm{sec}$. For each test specimen, an extensometer was fixed on the center of its gauge length. The test speed, maximum load, and other test parameters were fed to the test program. After completing the specimen failure, the obtained data points were used to draw stress-strain behavior for each specimen.

\section{Ballistic Tests and Measurements}

Ballistic tests were performed in order to determine the projectile impact and post-perforating velocities for the different tested targets. The principle of projectile velocity measurement was essentially based on measuring the time of its flight over a fixed distance (reference base). Breaking or connecting of electric circuits detected projectile arrival at a predetermined base. The measured velocity represented the velocity at the midpoint of the reference base; it was equal to the reference base divided by the measured time.

Projectile impact velocity was frequently measured at a close distance from point of impact. Because of the distance between the midpoint of reference base and target surface was small, the measured velocity was considered as the impact velocity of projectile. Projectile arrival was detected by the breaking of photocell electric circuits and the velocity measuring system could display the measuring time or projectile velocity directly on a PC screen.

The post-perforation velocity of the projectile was determined using velocity measuring frames Each frame, which detected the projectile arrival, was connected to two-channel oscilloscope. When the projectile passed through each of the measuring frame, it connected an electric circuit and gave a signal to the oscilloscope. The time difference between the two signals was recorded and used to determine the projectile residual velocity.

The ballistic experiments were performed in the ballistic shooing range, which had provisions for the measurement of projectile impact and post-perforation velocities, respectively. As shown in Fig. 1, the ballistic set-up mainly consists of: ballistic rifle, impact velocity and post-perforation velocity frames with their respective electronic measuring instruments, and target mount.

Small caliber projectiles having different impact velocities were fired against each constructed target; these velocities ranged from $200-600 \mathrm{~m} / \mathrm{s}$. The change in propellant charge mass was used to vary the projectile impact velocity. For each charge mass, a set of projectiles was fired against each tested target. Both the projectile impact and residual velocities, respectively, were measured using the velocity measuring systems used. Because of the barrel wear, the recorded impact velocities for each charge were slightly varied from shot to another. Therefore, close measurements of minimum three shots having a difference in between about $\pm 5 \mathrm{~m} / \mathrm{s}$ were considered; their average represented the projectile impact velocity. In addition, the average of the corresponding measured residual velocities was evaluated and taken as the projectile residual velocity.

\section{Post-Firing Examinations}

These were mainly concerned with the arrangement and the configurations of the set up, the projectile, and the target elements after perforation. After each firing test, the test set up was examined to make sure that all connections were not damaged by the projectile or by its fragments. Examining the recovered projectile after perforation of each tested target was very 
Table 1. Main data of used epoxy.

\begin{tabular}{|c|c|c|c|}
\hline Fabric type & Exoxy base & Eooxy hardener & $\begin{array}{c}\text { Mixing ratio } \\
\text { (base: harclener) }\end{array}$ \\
\hline kevlar-129 & Araldite CY 219 & HY 5161 & $2: 1$ \\
\hline
\end{tabular}

Table 2. Properties of the used fabric type.

\begin{tabular}{|c|c|c|c|c|c|}
\hline $\begin{array}{l}\text { Fabric } \\
\text { sype }\end{array}$ & $\begin{array}{l}\text { Tensile } \\
\text { modulus } \\
\text { [CPal }\end{array}$ & $\begin{array}{l}\text { Tensile } \\
\text { strengith } \\
\text { (GPa) }\end{array}$ & $\begin{array}{l}\text { Starin to } \\
\text { failure } \\
{[\% \%]}\end{array}$ & $\begin{array}{l}\text { Bensity } \\
\text { grim }\end{array}$ & $\begin{array}{l}\text { Operating } \\
\text { temp. } \\
{[\mathrm{i} G]}\end{array}$ \\
\hline kevlar-129 & 62 & 3.79 & 3.6 & 1440 & 500 \\
\hline
\end{tabular}

Table 3. Main characteristics of the manufactured composite.

\begin{tabular}{|c|c|c|c|c|c|c|}
\hline $\begin{array}{l}\text { Composite } \\
\text { ype }\end{array}$ & $\begin{array}{l}\text { Number: } \\
\text { layers: } \\
\text { li: }\end{array}$ & $\begin{array}{l}\text { Thick of } \\
\text { composite } \\
\text { hic } \\
\text { minl }\end{array}$ & $\begin{array}{l}\text { Piber } \\
\text { mass, } \\
\text { mi: }\end{array}$ & $\begin{array}{l}\text { Composite } \\
\text { mass; } \\
m_{c}: \\
{[\mathrm{d} !}\end{array}$ & 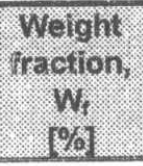 & $\begin{array}{l}\text { Density } \\
\text { Pcim }\end{array}$ \\
\hline \multirow{3}{*}{ kevlar/epoxy } & 3 & 3 & 61 & 110 & 55 & 883 \\
\hline & 9 & 9 & 177 & 319 & 54.5 & 953 \\
\hline & 15 & 15 & 291 & 510 & 56 & 982 \\
\hline
\end{tabular}

important in order to determine the degree of its deformation. This depended mainly on total thickness of target and projectile impact velocity. For thin duralumin plate, the petals height and its number as well as the perforation diameters of projectile into the plate were measured. Backing composite was similarly examined in order to determine the failure mode. All interesting features related to target failure mode and projectiles are photographed for the analysis of test results.

\section{ANALYTICA MODEL}

The present model consists of two main parts as described before. In this model, the projectile The present model consian a cylindro-conical shape with a diameter $d_{1}\left(=2 r_{1}\right)$ and a mass $\mathrm{m}$. The target configuration consists of thin metallic plate and composite, in order. The initial thickness of metallic plate is denoted by $h_{0}$, whereas the thickness of composite is denoted by $h_{c}$. The present model could be used to describe the penetration process through a composite only by setting the thickness of thin metallic plate to equal zero. In the following, the main assumptions as well as the model structure and its main equations are introduced.

\section{Main Assumptions}

- The amount of energy needed for extension of radial cracks is small and the source of energy dissipation is the plastic deformation of the thin metallic plate. 
- The projectile is rigid, non-deformable body. Stress and deformation gradients do not exist in the target thickness direction.

- The force exerted by the moving nose of the projectile is always applied at the tip of petal in the direction normal to the plate.

- Geometrical effects due to large deformations are neglected. i.e. the analysis is linear.

- The plate material is regarded as rigid, ideally plastic, so that no deformation occurs when the bending moment at the petal cross-section is smaller than the plastic moment.

- Projectile impacts are only considered in which the initial kinetic energy is much larger than the maximum elastic energy that the target plate can absorb. Hence, only plastic work is taken into account in the energy balance.

- The speed of crack propagation is always higher than the plastic hinge velocity.

- The thin metallic plate is penetrated without supporting from the composite. Therefore, the residual velocity of the projectile after perforating this plate is considered as the impact velocity for the backed composite.

- Textile/epoxy composite is homogenous and isotropic elastic.

- The laminate consisting the composite is deformed upon impact into a conical shell with straight sides. The failure mechanism of composite is due to tensile failure of its fiber.

- Frictions between yarns or projectile and composite are neglected.

- The epoxy is brittle and broken locally upon impact. Therefore, the projectile is assumed to penetrate the textile under the point of impact. This textile has a thickness $h_{c}$, which represents the total thickness of composite layers.

\section{Model Structure and Main Equations}

Modeling penetration of a thin metallic plate

The penetration process consists of two phases; these are (i) crack propagation during petalling process, and (ii) petal bending.

\section{(i) Crack propagation during petalling process}

Upon impact of projectile into a thin plate, star shape cracks are formed. These cracks propagate outwards under the pressure of the moving projectile. After partial perforation, the moving mass of the projectile tends to enlarge the circumference of the initial hole; the hoop stress is thus responsible for further radial extension of the cracks. The analytical formula representing the amount of energy spent to extend the star-shaped crack $W_{c}$ is derived as [1]:

$$
W_{c}=G_{t},
$$

where

$$
\mathrm{G}=\frac{\pi \sigma^{2} \mathrm{FF}^{2}(\mathrm{n})}{\mathrm{E}},
$$

and

$$
A_{t}=2 n_{o} a,
$$

$G$ is the amount of energy per unit crack area needed for crack extension, $A_{t}$ is the total area of cracks, $\sigma$ is the strength of plate material, $a$ is the length of crack, $F(n)$ is a function of petal number $n$, and $E$ is the young's modulus of plate material.

Substituting for $\sigma=\sigma_{y}$ in Eqn. (1)a, the upper bound of the energy $W_{c}$ is represented by:

$$
W_{c}=\frac{2 \pi n h_{\circ}}{E}\left(a \sigma_{y} F(n)\right)^{2},
$$

where $\sigma_{y}$ is the yield strength of plate material. 
(ii) Petal bending

Since the petals are initiated at the moment of impact and grow with outward propagation of crack, petal is considered as a cantilever beam of constant thickness and triangular with each successive motion of projectile. The fixed end of this beam moves outwards shape with each successive mot crack, cf. Fig. 2a. There are two stages in the absorption (a) during the plastic hinges motion until the cracks are arrested, and (b) process; these are: (a) during the plastion until they reach the root of the petals, cf. Fig. $2 b$.

during the subseque The petals still possess kinetic energy; therefore, additional motion will take place. Rigid and petals about their root by an angle $\theta_{2}$ occur at the end of second stage, which rotations of pretals absage of the projectile. If the petal still having some residual kinetic energy, especially for thin plates, the total rotations of petals exceed the angle $\theta_{2}$.

To determine the energy absorbed in the first stage, the problem is adapted to a triangular cantilever beam as shown in Fig. 2c. Then, the plastic moment for a cantilever beam of constant thickness $h_{0}$ and length $\mathrm{l}$ is given by:

$$
M_{p}=\sigma_{y} \frac{B h_{o}{ }^{2}}{4} \frac{x}{1}
$$

where $x$ is the distance of travel of plastic hinge after time $t$, and $B$ is the base of petal width The width of petal $b$ at a distance $x$ from the tip is given by:

$$
\mathbf{b}=\mathbf{B} \frac{\mathbf{x}}{\mathbf{I}}
$$

The number of formed petals is assumed, each petal is struck at the tip by a mass equal to that of the projectile divided by the number of petals. According to Johnson [11], the velocity of the striking mass $v_{1}$, after the hinge reaches the root of petal, is represented by:

$$
V_{1}=V_{1} /(1+n \mu / 3 m)
$$

where $V_{1}$ is the impact velocity, and $\mu$ is the mass of cantilever petal. The petal mass is given by (cf. Fig. 2c):

$$
\mu=\rho h_{0} B l / 2 \text {, }
$$

where $\rho$ is the density of plate material. The width of petal is given by:

$$
B=2 \pi a / n .
$$

Substituting by Eqns. (6) and (7) after putting l=a into Eqn. (5) results in:

$$
V_{1}=V_{1} /(1+k),
$$

where

$$
k=\pi \rho h_{0} a^{2} / 3 m \text {. }
$$

For the second stage, petals rotation about their fixed end takes piace. The energy balance for this stage is:

$$
n\left[M_{p}^{*}\left(\theta_{2}-\theta_{1}\right)+\Delta W_{R}\right]=\frac{m}{2}\left(V_{1}^{2}-V_{1}^{2}\right),
$$


where $M_{p}{ }^{*}$ is the full plastic moment at the petal root which is obtained by substituting into Eqn. (3) for $x=1, \Delta W_{R}\left(=W_{R 2}-W_{R 1}\right)$ is the change of rotational energy of petal during the second stage of motion, and $v_{f}$ is the final velocity of projectile after perforating the thin metallic plate. The rotational energy of the petal at the beginning of the second stage $W_{R 1}$ is given by:

$$
W_{R 1}=\frac{m}{2 n} V_{i}^{2} \frac{k}{2(1+k)^{2}}
$$

The rotational energy of petal at the end of second stage $W_{R 2}$ is:

$$
W_{R 2}=\frac{1}{2} I \omega_{r}{ }^{2},
$$

where

and

$$
I=\left.\frac{1}{12} B\right|^{3} h_{0} \rho=\frac{1}{6} \frac{\pi a^{4} h_{\circ} \rho}{n},
$$

$$
\omega_{r}=\frac{V_{n}}{a}=\frac{V_{f} \cos \theta_{2}}{a} \text {. }
$$

$I$ is the moment of inertia about the base, and $\omega_{\mathrm{r}}$ is the angular velocity of petal.

Substituting by Eqns. (10) and (11) into Eqn. (9) yieids:

$$
V_{f}=\sqrt{\frac{\frac{2(1+k)^{2}+k}{2(1+k)^{2}} V_{i}^{2}-\frac{4 \pi \sigma_{y} a h_{0}^{2}\left(\theta_{2}-\theta_{1}\right)}{m}}{1+\frac{\pi a^{2} h_{0} \rho \cos ^{2} \theta_{2}}{6 m}}}
$$

The ballistic limit $V_{50}$ associated with Eqn. (12) is obtained by putting $V_{f}=0$ so that:

$$
V_{50}=2 h_{0}(1+k) \sqrt{\frac{2 \pi \sigma_{y} a\left(\theta_{2}-\theta_{1}\right)}{m(2+k)(1+2 k)}}
$$

The previous equations are derived without considering the energy dissipated in plate dishing. This energy is denoted by $W_{p}$ and is represented by [12]:

$$
W_{p}=\int_{V}\left(\int \sigma_{r} d \varepsilon_{r}\right) d Z
$$

where $\sigma_{\mathrm{r}}$ and $\varepsilon_{\mathrm{r}}$ are radial stress and strain, respectively, and $Z$ is the plate volume. The lower limit is taken as value of crack length $a$, whereas the upper limit is taken as infinity. Substituting for $\sigma_{\mathrm{r}}=\sigma_{\mathrm{y}}$ and adjusting Eqn. (12) to include the dishing energy term $W_{\mathrm{p}}$ leads to:

$$
V_{f}=\sqrt{\frac{\frac{2(1+k)^{2}+k}{2(1+k)^{2}} V_{1}^{2}-\frac{4 \pi \sigma_{y} a h_{o}{ }^{2}\left(\theta_{2}-\theta_{1}\right)}{m}-\frac{2 W_{p}}{m}}{1+\frac{\pi a^{2} h_{0} \rho \cos ^{2} \theta_{2}}{6 m}}}
$$

The magnitude of ballistic limit including the dishing energy term is represented by: 


$$
V_{50}=\frac{2}{m}\left[W_{c}+W_{p}+n M_{p}^{*}\left(\theta_{2}-\theta_{1}\right)\right]^{1 / 2}
$$

\section{Modeling penetration of a composite}

The final velocity of the projectile after perforating the duralumin plate is considered herein as the impact velocity for a composite. Upon the projectile impacting the fabric, a conical deformation is resulted in analogous to the $V$-shaped deformation. Figure $3 a$ shows a horizontal yarn transversely impacted by projectile $A$ traveling in the vertical direction at velocity $V$. Due to the impact, a longitudinal strain wave is initiated and propagated horizontally with velocity $\mathrm{C}$, in opposite directions away from the impact point $A$. Concurrently, a transverse wave of velocity $\bar{U}$ is generated which causes the inverted $V$-shaped deformation pattern to propagate to point $\mathrm{P}$ at time $\mathrm{t}$.

The strain wave velocity $C$ relative to such unstrained points on the yarn, at more distance away from ' $\mathrm{C} t$ ' is given by:

$$
C=\sqrt{\frac{1}{M}\left(\frac{d T}{d \varepsilon}\right)_{\varepsilon=0}},
$$

where $M$ is the mass per unit length of the unstrained yarn, and $(d T / d \varepsilon)_{\varepsilon=0}$ is the initial slope of the yarn tension-strain curve. The vertical velocity $V$ and the velocity of transverse wave front $\bar{U}$ are represented by [2]:

$$
V=C \sqrt{\varepsilon(1+\varepsilon)[\sqrt{\varepsilon(1+\varepsilon)}-\varepsilon]^{2}}
$$

and

$$
\overline{\mathrm{U}}=C \sqrt{[\sqrt{\varepsilon(1+\varepsilon)}-\varepsilon]^{2}},
$$

where $\varepsilon$ is the yarn strain. The velocity $V$ at $\varepsilon=0$ is represented by $V_{f}$, the velocity at which a complete penetration of thin metallic plate is occurred.

Equation (19) derived by Vinson and Zukas [6] is modified by Taylor and Vinson [2] who represented the velocity of transverse wave front as a function of projectile velocity $V$ as:

$$
\bar{U}=64+(0.74 \times V) \text {. }
$$

The linear conical shell theory is used to drive the equations necessary for determining the displacements, stress resultants, and couples for the generalized case of truncated conical shell under axially symmetric loading. The axial displacement of conical shell $U_{\text {tot, }}$ at incremental time $\Delta t$ is represented by (cf. Fig. 3b):

$$
U_{\text {tot }}=V \Delta t=\frac{r_{1} \bar{V}}{E_{c} h_{c} \sin \beta \cos ^{2} \beta} \ln \left(r_{2} / r_{1}\right),
$$

where $V$ is the projectile velocity, $r_{1}$ is projectile radius, $\bar{V}$ is the axial load per unit of circumference, $E_{c}$ is elasticity modulus of the fabric, $h_{c}$ is the total thickness of the fabric, $\beta$ is the rotation angle of the fabric with respect to the normal of the middle surface, and $r_{2}$ is the product of the transverse wave velocity $\bar{U}$ and time $t$ in addition to the radius $r_{1}$. Equation. (21) can be used to determine the axial load $\bar{V}$ caused when the fabric is elongated an amount $U_{\text {tot. }}$ as follows: 


$$
\bar{V}=\frac{E_{c} h_{c}}{r_{1}} \frac{U_{\text {tot. }} \sin \beta \cos ^{2} \beta}{\ln \left(r_{2} / r_{1}\right)}
$$

The rotational angle $\beta$ is determined by:

$$
\beta=\tan ^{-1}\left(r_{2} / U_{\text {tot. }}\right) \text {. }
$$

The projectile acceleration is calculated by dividing the circumferential force by the projectile mass as:

$$
a_{p}=-2 \pi r_{1} \bar{v} / m
$$

In addition, the maximum strain at $r=r_{1}$ is represented by conical shell theory as:

$$
\varepsilon_{y}\left(r_{1}\right)=\varepsilon_{y_{\text {max. }}}=\frac{U_{\text {tot. }} \cos \beta \sin \beta}{r_{1} \ln \left(r_{2} / r_{1}\right)} .
$$

As the projectile deflects the fabric, both the level of strain and strain rate change considerably with time. Hence, the modulus of elasticity of the fabric will also change with time. From Eqn. (19) and knowing the strain of the fabric from Eqn. (25), the instantaneous modulus of elasticity $E_{c}$ is calculated.

\section{Input Data and Outcomes of the Present Model}

The input data to the two-part model for describing the projectile penetration into a target consisting of thin duralumin plat backed by a composite are: (i) radius, mass and impact velocity of projectile, (ii) crack length, number of petals, rotational angels of petal $\theta_{1}$ and $\theta_{2}$, respectively, density and yield strength of duralumin plate material, and (iii) strain to failure and density of a fabric material. The present model could describe the projectile penetration into composite target only; the input data in this case consist of items (i) and (iii).

The solution procedures of the two-part model can be shown in Fig. 4. The output of the firstpart of the model is the projectile velocity $V_{f}$. However, the time is taken as independent variable for the second part of the model. The procedures of the solution for the second part are repeated for each incremental time $\Delta t$. The penetration process terminates when either the projectile velocity is zero, or the strain calculated using Eqn. (25) reaches the failure strain of the fabric $\varepsilon_{f}$, which, in turn, provides the projectile residual velocity $V_{r}$.

The model is capable of predicting the projectile energy loss and its distribution in the different forms during thin metallic plat perforation at each impact velocity. In addition, the time histories of the transverse wave velocity, angle of fiber, strain of fiber, modulus of elasticity, and the axial force acting on fiber during its penetration into a backing composite could be predicted. In the following, the predictions of the model are only concerned with the projectile velocity after perforating a metal/composite target at each impact velocity.

\section{RESULTS AND DISCUSSIONS}

The present results are divided into: (i) results of target material characterization, (ii) ballistic firing test results, (iii) post-firing examinations of tested targets and recovered projectiles, (iv) comparison between the obtained experimental measurements and the corresponding predictions of the present model, and $(v)$ determination of target configurations capable of defeating the projectile at its highest impact velocity used. 


\section{Results of Target Material Characterization}

Figure 5 shows the stress-strain curves for kevlar/epoxy composites consisting of 1,3 , and 6 layers. These curves show that the values of strain to failure and the tensile strength are varied with thickness of composite. In addition, the relation between tensile stress and strain is non linear for each thickness of tested composite. Table 4 shows the average tensile test results for each thickness of tested composite. The modulus of elasticity for each thickness of tested composite was deduced from its stress-strain behavior. A regression analysis between number of layers and corresponding strains for the tested specimens is extrapolated to determine the strains of composites with 9 and 15 layers, respectively. The tensile test properties for the used thicknesses of the duralumin plates are also listed in Table 4 [13].

\section{Ballistic Firing Test Results}

The ballistic test results due to the impact of different constructed duralumin/composite targets by small caliber projectiles having different impact velocities are presented. Symbols and digits are used to designate the tested targets; the symbols represent the duralumin and kevlar/epoxy composite, whereas the digits represent their thickness, respectively. For example, $\mathrm{Al}-1.6+\mathrm{K}-3$ means that the target consists of $1.6 \mathrm{~mm}$-thick duralumin plate backed by $3 \mathrm{~mm}$-thick kevlar/epoxy composite. Both the projectile velocity drop and energy loss are chosen to represent the ballistic resistance of constructed targets to penetration.

Figure 6 depicts the change of projectile residual velocity with impact velocity for the different total thickness of duralumin/composite targets. The present figure shows that the residual velocity increases with increasing impact velocity for each duralumin/composite target. In addition, the plotted results shows that the ballistic limits for duralumin/composite targets with total thickness of 10.6 and $16.6 \mathrm{~mm}$ are 350 and $390 \mathrm{~m} / \mathrm{s}$, respectively.

Figure 7 plots the change of the velocity drop $\Delta \mathrm{V}$ with projectile impact velocity for the constructed duralumin/composite targets. For each total target thickness, the present figure shows that the velocity drop decreases with increasing the projectile impact velocity. However, the velocity drop at the initial points for targets with total thicknesses of 10.6 and $16.6 \mathrm{~mm}$ are equal to their impact velocities, respectively.

Figure 8 shows the relation between the projectile energy loss and projectile impact velocity for the duralumin/composite targets with different total thicknesses. For each total target thickness, it is seen from the figure that the projectile energy loss increases with impact velocity. This may be attributed to the strain rate of the composite, which increases with impact velocity. The increase of strain rate increases the target resistance to penetration. Therefore, the projectile dissipates more energy to defeat the target at high impact velocity. For the same impact velocity, the present figure shows that the projectile energy loss increases with total target thickness. This may be due to the thickness of composite supporting the penetrating duralumin plate. The trends of the present results are similar to that of Shim [14].

Figure 9 depicts the drop in projectile velocity as function of total thickness of duralumin/composite target at $V_{i}=400$ and $575 \mathrm{~m} / \mathrm{s}$, respectively. At each impact velocity, it is clear from the figure that the drop in projectile velocity increases with increasing the total target thickness. Moreover, the drop in projectile velocity decreases with increasing the impact velocity at each target thickness.

Figure 10 plots the change of projectile energy loss as function of total target thickness at $V_{i}=$ 400 and $575 \mathrm{~m} / \mathrm{s}$, respectively. It is seen from the figure that the projectile energy loss increases at each impact velocity with increasing the target thickness. In addition, the energy loss increases at each target thickness with increasing the impact velocity. This may be attributed to 
Table 4. Tensile test results for the different thicknesses of kevlar/epoxy composites and duralumin.

\begin{tabular}{|c|c|c|c|c|c|c|}
\hline Material & $\begin{array}{c}\text { No. of } \\
\text { Layer } \\
\mathbf{N}\end{array}$ & $\begin{array}{c}\text { Thick. } \\
{[\mathrm{mm}]}\end{array}$ & $\begin{array}{c}\text { Strain to } \\
\text { failure, } \\
\boldsymbol{\varepsilon}_{\mathbf{f}} \\
{[\%]}\end{array}$ & $\begin{array}{c}\text { Tensile } \\
\mathbf{s t r e s s ,} \\
\boldsymbol{\sigma} \\
{[\mathrm{MPa}]}\end{array}$ & $\begin{array}{c}\text { Elasticity } \\
\text { modulus, } \\
{[\mathrm{GPa}]}\end{array}$ & $\begin{array}{c}\text { Brinell } \\
\text { hardness } \\
{[\mathrm{HB}]}\end{array}$ \\
\hline kevlar/epoxy & 1 & 1 & 2.2 & 227 & 10.3 & - \\
Composite & 3 & 3 & 2.9 & 272 & 9.4 & - \\
\hline \multirow{2}{*}{ Duralumin } & 6 & 6 & 3.1 & 375 & 12.1 & - \\
& 1 & 1.6 & 11.76 & 383 & 3.27 & 109 \\
& 1 & 3 & 11.4 & 407 & 3.57 & 117 \\
\hline
\end{tabular}

the strain rate of the composite, which increases with impact velocity. Therefore, the target resistance to penetration increases with impact velocity.

Form the introduced ballistic test results, it can deduce that: (i) the constructed targets with total thicknesses of 10.6 and $16.6 \mathrm{~mm}$ defeat the used projectile at $V_{i}=350$ and $390 \mathrm{~m} / \mathrm{s}$, respectively. The areal densities of such targets are 12.98 and $19.13 \mathrm{~kg} / \mathrm{m}^{2}$, respectively, (ii) by increasing the thickness of duralumin plate; the used projectile could be defeated at the highest impact velocity used, and (iii) another light material with high mechanical properties such as ceramic or titanium alloy is recommended to be used with kevlar/epoxy composite target to improve the ballistic resistance and decreasing the areal density of the target needed to defeat the used projectile at its highest velocity.

\section{Post-Firing Examination Results}

The recovered projectiles after perforating the duralumin/composite targets at $V_{i}=400-500 \mathrm{~m} / \mathrm{s}$ were examined. The perforated projectiles are significantly deformed during the penetration process. The projectiles noses are effectively bent as shown in Fig. 11.

The visual inspection of each duralumin plate after terminating the penetration process showed that the petalling failure mode is always occurred. The number of petals is ranged from six to eight, as shown in Fig. 12. Moreover, Fig. 13 shows a target consisting of $1.6 \mathrm{~mm}$-thick duralumin plate backed by $15 \mathrm{~mm}$-thick kevlar/epoxy composite; the projectile arrested in target at $V_{i}=390 \mathrm{~m} / \mathrm{s}$ can be shown.

\section{Comparison between Measured and Predicted Results}

In the following, the experimental measurements obtained due to the impact of different tested targets by a small caliber projectile with different impact velocities are compared with the predictions of the analytical model. Moreover, the absolute relative differences between the measured and predicted results are calculated. The present model is run to predict the projectile residual velocities after perforating the duralumin/composite targets with different total thicknesses due to their impact by a projectile with different velocities used. Projectile mass and its radius are fed to the program, whereas the data of each tested target that fed to the program are listed in Table 5

The input data include some parameters needed to be determined based on the postperforation examinations of duralumin plate faced each composite thickness. These parameters are: number of petals, rotational angle at the end of penetration process and crack length. The 
Table 5. Input data of targets necessary to run the present analytical model.

\begin{tabular}{|c|c|c|c|c|}
\hline \multirow{2}{*}{ Material } & \multirow{2}{*}{ Parameter } & \multicolumn{3}{|c|}{ Target designation } \\
\hline & & $\mathrm{Al}-1.6+\mathrm{K}-3$ & $\mathrm{Al}-1.6+\mathrm{K} 9$ & Al-1.6+K-15 \\
\hline \multirow{7}{*}{ Duralumin } & Plate thickness, $h_{\circ}[\mathrm{mm}]$ & \multicolumn{3}{|c|}{1.6} \\
\hline & Yield strength, $\sigma_{y}[\mathrm{MPa}]$ & \multicolumn{3}{|c|}{225} \\
\hline & Density, $\rho\left[\mathrm{kg} / \mathrm{m}^{3}\right]$ & \multicolumn{3}{|c|}{2750} \\
\hline & Number of petals, $n$ & \multicolumn{3}{|c|}{8} \\
\hline & Initial rotational angle of petal, $\theta_{1}\left[{ }^{\circ}\right]$ & \multicolumn{3}{|c|}{2} \\
\hline & Initial rotational angle of petal, $\theta_{2}\left[{ }^{\circ}\right]$ & 50 & 90 & 90 \\
\hline & Crack length, a [mm] & 7.2 & 11 & 12 \\
\hline \multirow{3}{*}{$\begin{array}{c}\text { Composit } \\
e\end{array}$} & Density of Fabric, $\rho_{\mathrm{f}}\left[\mathrm{kg} / \mathrm{m}^{3}\right]$ & \multicolumn{3}{|c|}{1440} \\
\hline & Thickness $h_{c}[\mathrm{~mm}]$ & 3 & 9 & 15 \\
\hline & Strain to failure, $\varepsilon_{\mathrm{f}}[\%]$ & 2.9 & 3.3 & 3.6 \\
\hline
\end{tabular}

rotational angle at the crack initiation used by Landkof and Goldsmith [1] for aluminum target with thicknesses close to that used duralumin plate is considered herein.

Figure 14 shows the predicted change of projectile residual velocity with impact velocity for different total thickness of duralumin/composite targets. For each target thickness, the measured residual velocities corresponding to different impact velocities are also depicted on the same figure. Good agreement is obtained between measured and predicted residual velocities over the used range of impact velocity. In addition, the model predicts the ballistic limits for Al-1.6+K-9 and $\mathrm{Al}-1.6+\mathrm{K}-15$ targets; these are found to be consistent with that determine experimentally. The previous results prove the predictive capabilities of the present model.

For each total target thickness, the predicted results of the present model are in good agreement with the corresponding experimental measurements. In addition, The maximum absolute relative difference between predicted and measured residual velocities is found to be $11.1 \%$ for Al-1.6+K-15 target at $V_{i}=400 \mathrm{~m} / \mathrm{s}$, whereas The maximum absolute relative differences are found to be $13.8 \%$ for Al-1.6+K-9 target at $V_{i}=371 \mathrm{~m} / \mathrm{s}$ and $9.2 \%$ for Al-1.6+K3 target at $V_{i}=292 \mathrm{~m} / \mathrm{s}$.

Figure 15 plots the predicted change of projectile energy loss ratio as function of impact velocity for the different duralumin/composite targets used. The measured energy loss ratios are also depicted on the same figure. Both the predicted and experimental measurements for each target thickness are in good agreement over the used range of impact velocity. Moreover, the maximum absolute relative difference between predicted and measured energy loss ratio is found to be $7.16 \%$ for Al-1.6+K-15 target at $V_{i}=387 \mathrm{~m} / \mathrm{s}$, whereas The maximum absolute relative differences are found to be $6.2 \%$ for Al-1.6+K-9 target at $V_{i}=437 \mathrm{~m} / \mathrm{s}$ and $6.5 \%$ for Al$1.6+\mathrm{K}-3$ target at $\mathrm{V}_{1}=365 \mathrm{~m} / \mathrm{s}$.

\section{Target Configurations Defeating the Projectile at Its Highest Impact Velocity Used}

From the previous results, it must be necessary to constructed, and test a target capable of defeating the projectile at $V_{i}=585 \pm 5 \mathrm{~m} / \mathrm{s}$. Two configurations were constructed and tested. These configurations are capable of defeating the projectile at this particular impact velocity. The 
projectile velocity of $585 \mathrm{~m} / \mathrm{s}$ represents its impact velocity for a target placed at $200 \mathrm{~m}$ from the muzzle. This distance is determined by predicting the trajectory of such a projectile.

Table 6 lists the target configurations, projectile impact velocity, residual velocity, and the areal densities of each tested target. Moreover, the corresponding predicted results using the present model are also listed in the same table. Post-firing examinations of the tested targets show that the bulge height at the back face of each target is small to avoid the trauma effect. By comparing the areal densities of the tested targets, the second target configuration can be selected to defeat the used projectile at its highest impact velocity used. Figure 16 shows the back face of Kevlar/epoxy composite and the face of third duralumin plate with thicknesses of 4 $\mathrm{mm}$ due to their impact by a projectile at $V_{i}=585 \mathrm{~m} / \mathrm{s}$. This figure shows a bulge in the back of composite and slight indent in the duralumin plate.

Table 6. Comparison between measured and predicted results due to the impact of the suggested target configurations with $V_{i}=585 \pm 5 \mathrm{~m} / \mathrm{s}$.

\begin{tabular}{|c|c|c|c|c|c|}
\hline \multirow{2}{*}{ Config. } & \multirow{2}{*}{ Target } & \multirow{2}{*}{$\begin{array}{l}\text { Impact } \\
\text { velocity, } \\
\text { Vil } \\
\text { [mis] }\end{array}$} & \multicolumn{2}{|c|}{$\begin{array}{l}\text { Residual velocity, V, } \\
{[\mathrm{m} / \mathrm{s}]}\end{array}$} & \multirow{2}{*}{$\begin{array}{l}\text { Areal } \\
\text { densities, } \\
\text { [Kg/m? }\end{array}$} \\
\hline & & & Measured & Predicted & \\
\hline 1 & $\mathrm{Al}-4+\mathrm{K}-15+\mathrm{Al}-4$ & 585 & 0 & 0 & 36.92 \\
\hline 2 & $\mathrm{Al}-3+\mathrm{K}-15+\mathrm{Al}-4$ & 590 & 0 & 0 & 34.15 \\
\hline
\end{tabular}

\section{CONCLUSIONS}

- The duralumin/composite target with total thickness of $10.6 \mathrm{~mm}$ is capable of defeating the used projectile at $V_{i}=350 \mathrm{~m} / \mathrm{s}$ whereas, a similar target configuration with total thickness of $16.6 \mathrm{~mm}$ can defeat the same projectile at $V_{i}=390 \mathrm{~m} / \mathrm{s}$. The areal densities of both targets are 12.98 and $19.13 \mathrm{~kg} / \mathrm{m}^{2}$, respectively. The ballistic performance of these targets could be increased by slightly increasing the thickness of duralumin plate.

- The amount of absorbed energy increases with increasing the target thickness and impact velocity. For example, the amount of absorbed energy by a total target thickness of $16.6 \mathrm{~mm}$ is 3.92 times the value that absorbs by a thickness of $4.6 \mathrm{~mm}$ at $V_{i}=575 \mathrm{~m} / \mathrm{s}$.

- The post-firing examination for all tested targets and their perforated projectiles, respectively, show that: (i) Yarns of kevlar are subjected to high strain that failed by tension. in addition, the duralumin plate is always failed by petalling, (ii) the damaged areas in kevlar/epoxy composites that backed duralumin plate are localized. This may be an advantage for the used composites rather than using its fabric alone, and (iii) the delamination between composite layers is significant at the lowest impact velocities used; this is decreased with increasing the impact velocity.

- For each tested target, the projectile residual velocities are compared with that of the corresponding predictions of the present analytical model. Good agreement is generally obtained.

\section{REFERENCES}

1. Landkof, B. and Goldsmith, W., "Petaliing of Thin Metallic Plates During Penetration by Cylindro-Conical Projectiles", Int. J. Solids Struct., Vol. 21, pp. 245-260 (1985). 
2. Taylor, W. A. and Vinson, J. R., "Modeling Ballistic Impact into Flexible Materials", J. AIAA, Vol. 28, No. 12, pp. (1992)

3. Waclawik, S., "Technology and Design Trends in U.S. Army Body Armor Board", Personal Armor System Symp. [PASS 98], Colchester, UK (1998).

4. Paul, B. and Zaid, M., "Mechanics of High Speed Projectile Perforation", J. Franklin Inst., Vol. 264, pp. 117-126 (1957).

5. Paul, B. and Zaid, M., "Normal Perforation of Thin Plates by Truncated Conical Projectiles', J. Franklin Inst., Vol. 265, pp. 317-335 (1958)

6. Vinson, J. R. and Zukas, J. A.," On the Ballistic Impact of Textile Body Armor", J. Appl. Mech., Vol. 42, pp. 263-268 (1975).

7. Zhu, G., Goldsmith, W. and Dharan, C. K., "Penetration of Laminated Kevlar by projectilesII. Analytical Model", Int. J. Solid Struct., Vol. 29, No.4, pp. 421-436 (1992).

8. Cunniff, P.M., "A Semi-empirical Model for the Ballistic Impact Performance of Textile Based Personnal Armor", J. Textile Res., Vol. 66, No.1, pp. 45-59 (1992).

9. Slepyan, L. I. and Stepanenko, M. V., "Penetration of Metal-Fabrics C.K. (1998).

Projectiles", Personal Armor System Symp. (PASS 98), Colch and Textiles", M. Sc. Thesis,

10. Salah, S. A., "Ballistic Resistance of Selected Composites M.T.C., Cairo, Egypt (2002).

11. Johnson, W. "Impact Strength of Material", Ch. 6, pp. 250-280, Edward Arnold (publishers) Ltd. (1972).

12. Calder, C. A. and Goldsmith, W., "Plastic Deformation and Po. 863-881, U. K. (1971). Resulting form Projectile Impact', Int. J. Solids Struct., (1990).

14. Shim, V. P., Tan, V. B. and Tay, T. E., "Modelling Deformation and Damage Characteristics of Woven Fabric under Small Projectile Impact" Int. J. Impact Engng. ,Vol. 16, No. 4, pp 585-605 (1995).

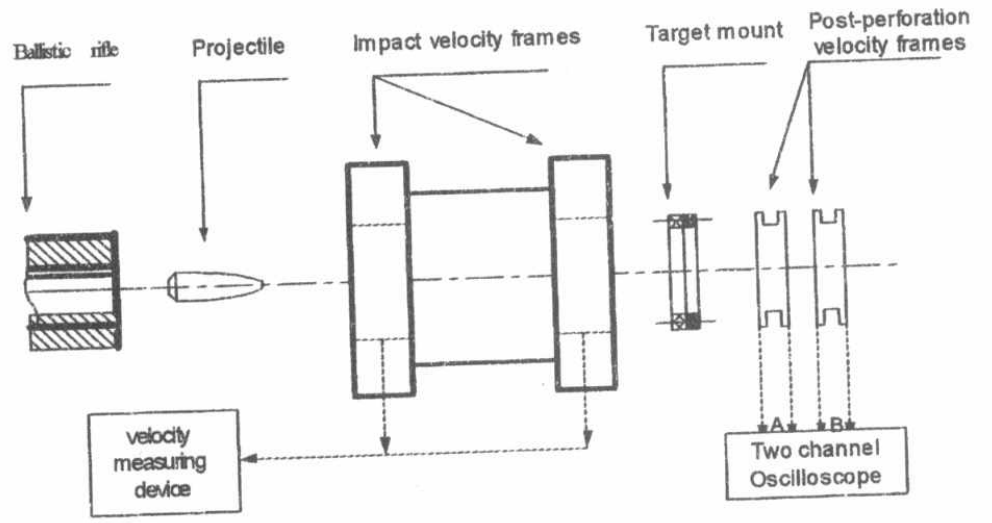

Fig. 1. A scheme of ballistic setup. 


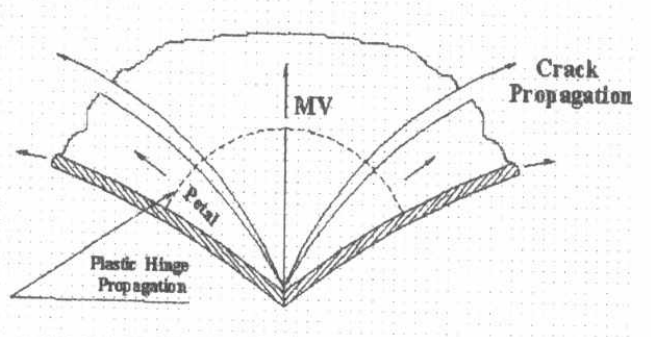

Fig. 2a. Propagation of cracks and plastic hinges [1].

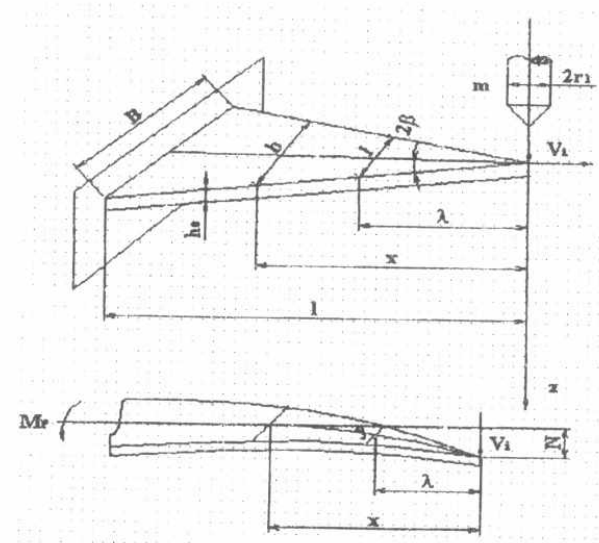

Fig. 2c. Petal dimensions and loads [1].

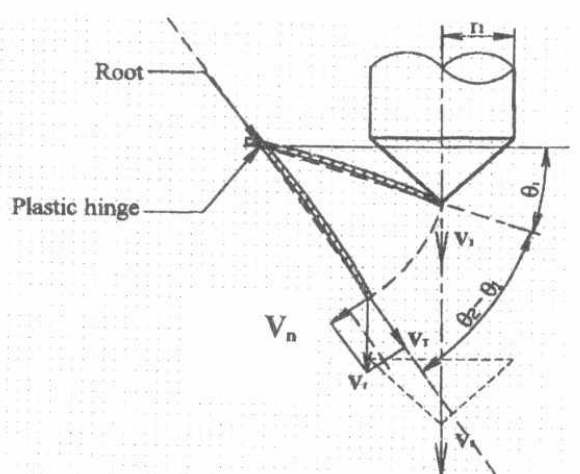

Fig. 2b. Arrival of plastic hinges to the root of the petal [1].

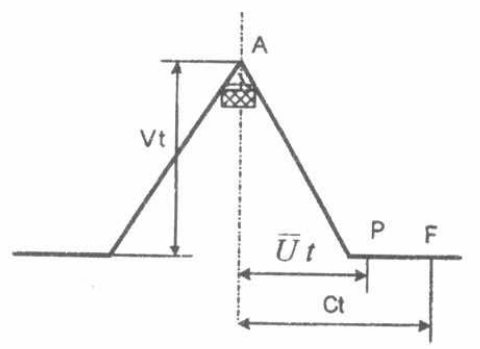

Fig. 3a. Horizontal yarn impacted by projectile [2].

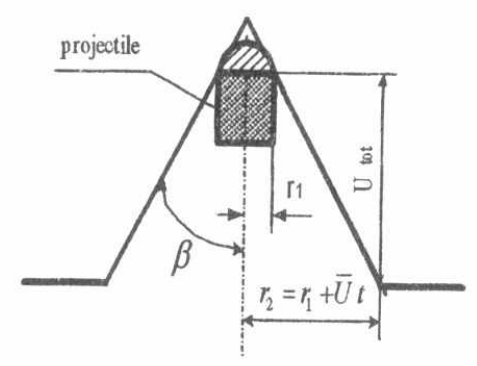




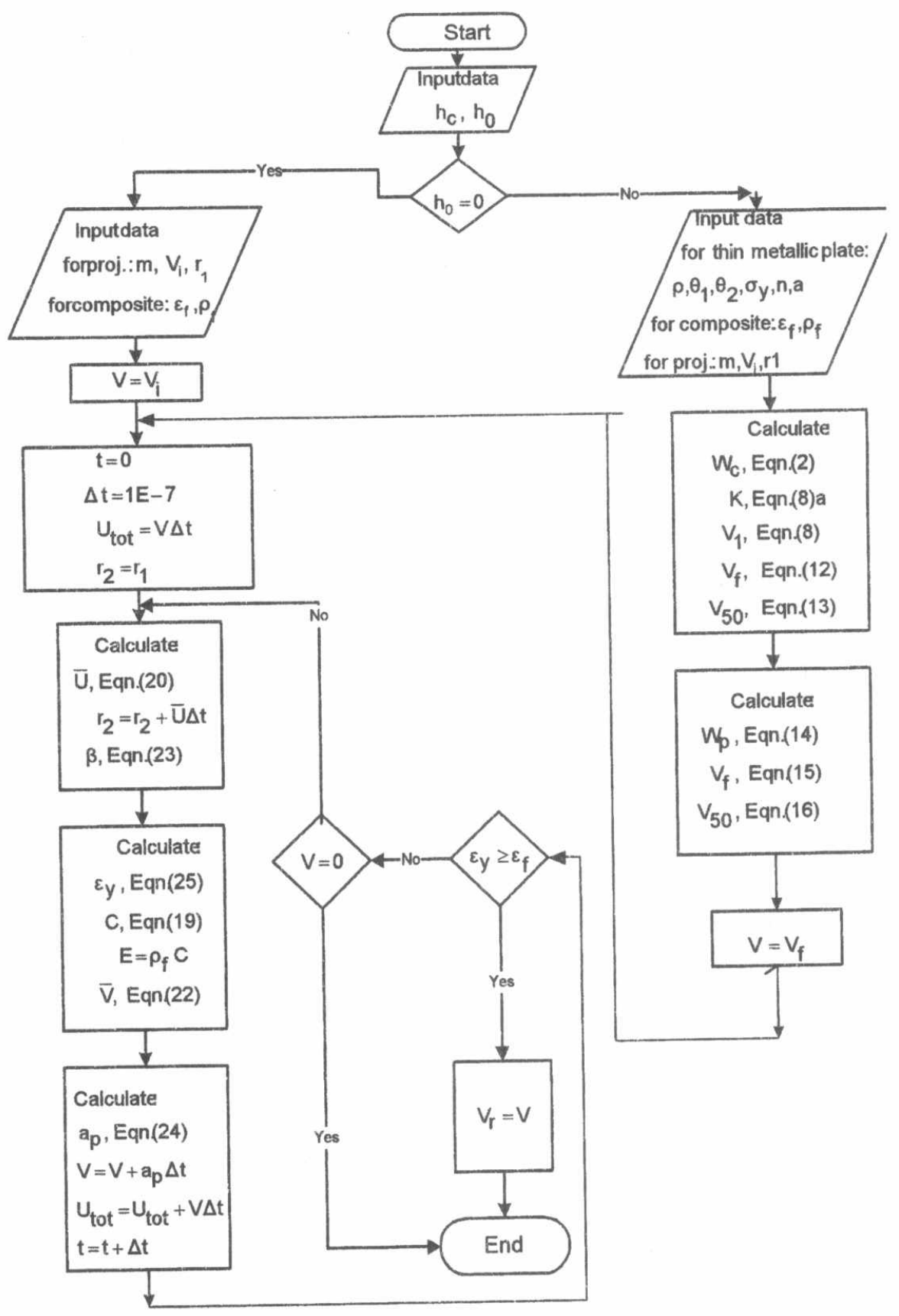

Fig. 4. Flow chart showing the procedures of solution for a metal/composite target or a composite target only. 


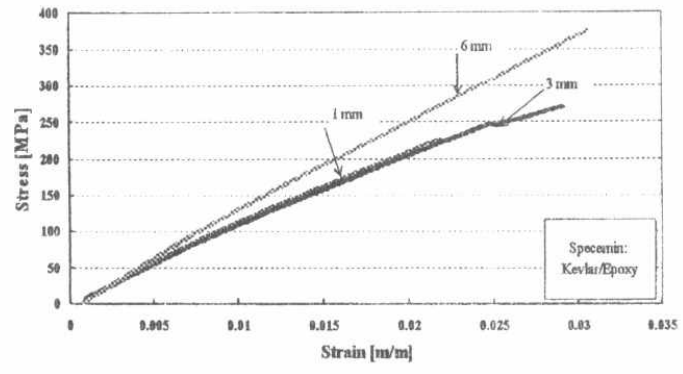

Fig. 5. Stress-strain curves for Kevlar/Epoxy composites with thicknesses of 1,3 and $6 \mathrm{~mm}$, respectively

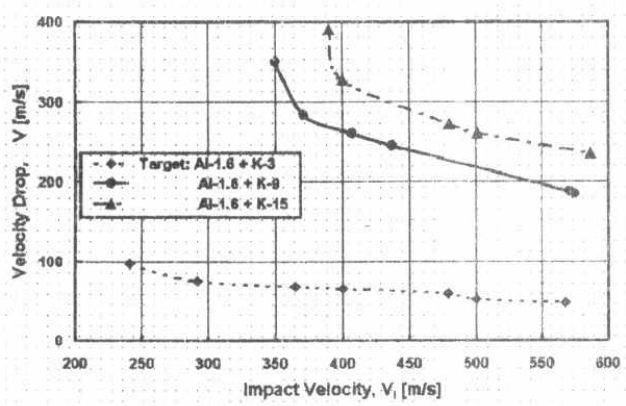

Fig. 7. Projectile velocity drop versus impact velocity for each constructed target.

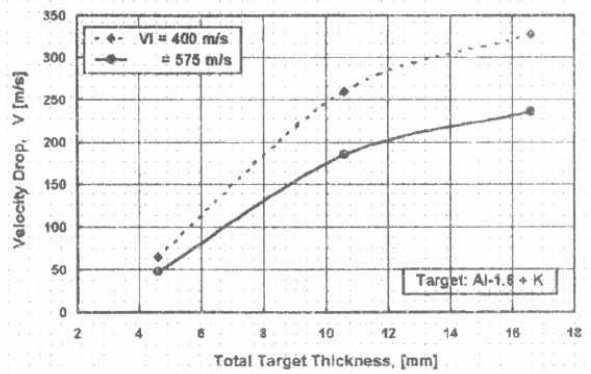

Fig. 9. Projectile veiocity drop versus total target thickness at $V_{i}=400$ and $575 \mathrm{~m} / \mathrm{s}$, respectively

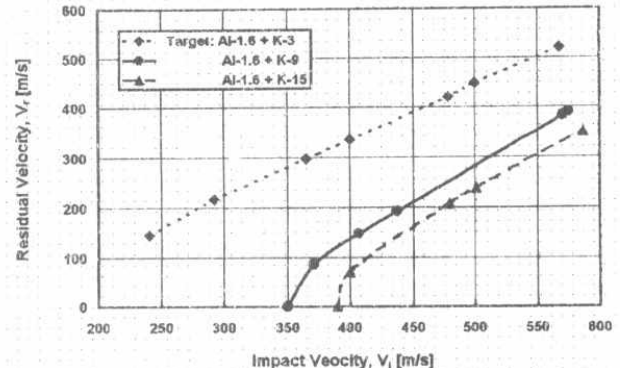

Fig. 6. The change of projectile residual velocity with impact velocity for each constructed target.

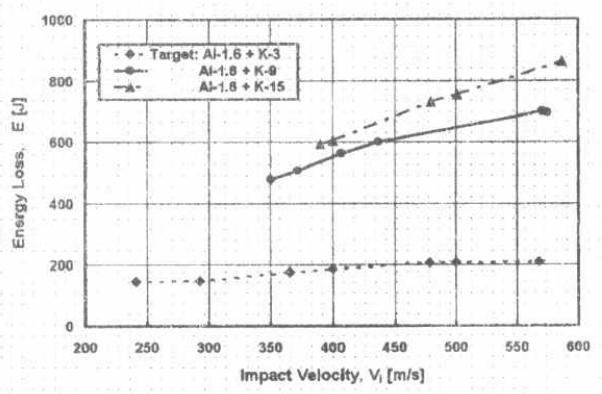

Fig. 8. Projectile energy loss versus impact velocity for each constructed target.

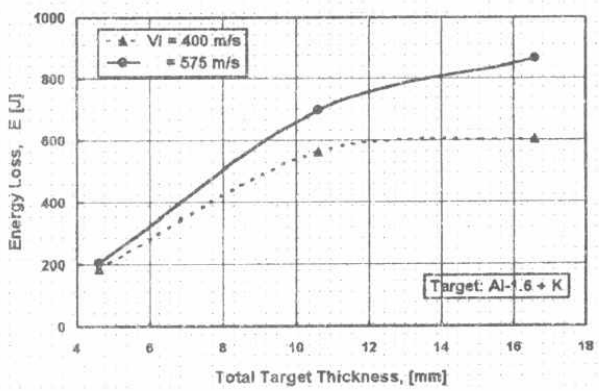

Fig. 10. Projectile energy loss versus total target thickness at $V_{i}=400$ and $575 \mathrm{~m} / \mathrm{s}$, respectively. 


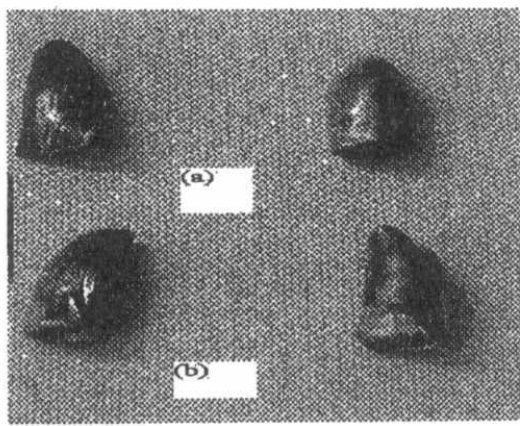

Fig. 11. Recovered projectiles after perforating: (a) $\mathrm{Al}-1.6+\mathrm{K}-9$, and (b) $\mathrm{Al}-1.6+\mathrm{K}-15$ targets at impact velocity ranged from $400-500 \mathrm{~m} / \mathrm{s}$.

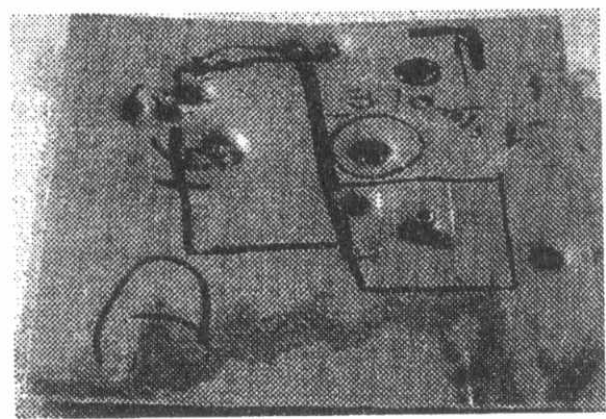

Fig. 13. Projectile arrested in an Al-1.6+ K-15 target at $V_{i}=390 \mathrm{~m} / \mathrm{s}$.

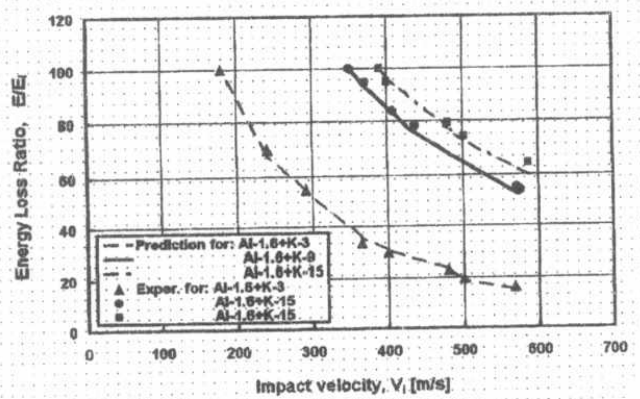

Fig. 15. Predicted and measured projectile energy loss ratio as function of impact velocity for different tested targets.

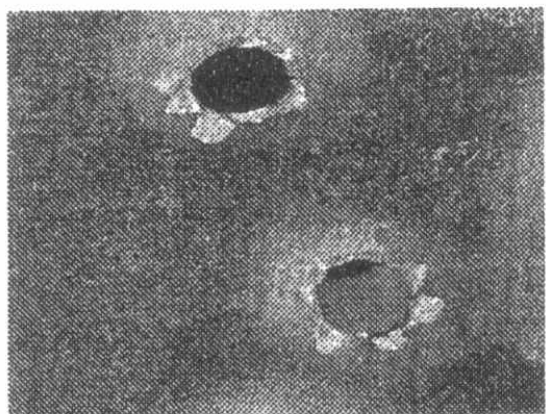

Fig. 12. Petal failure mode in a $1.6 \mathrm{~mm}$-thick duralumin plate.

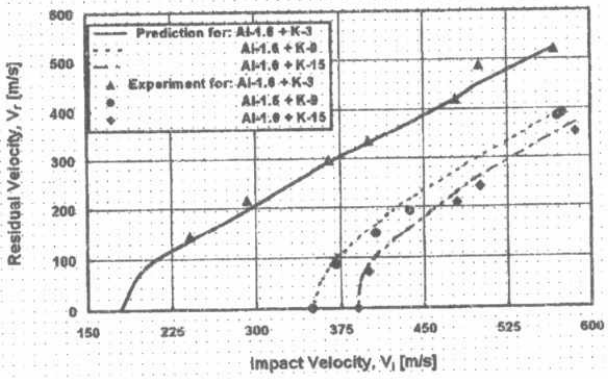

Fig. 14. Comparison between predicted and measured residual velocities as function of $V_{i}$ for different tested targets

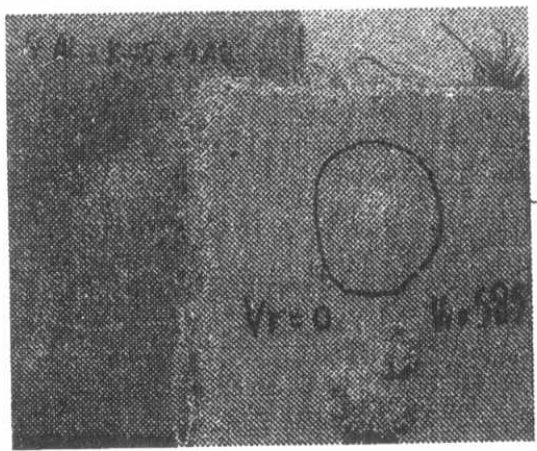

Fig. 16. $\mathrm{A} 4 \mathrm{Al}+\mathrm{K}-15+4 \mathrm{Al}$ target defeating the projectile at $V_{i}=585 \mathrm{~m} / \mathrm{s}$. 